\title{
VARIATION IN EL NIÑO CIRCULATION PATTERNS AND WINTER STORM IMPACTS IN SOUTHERN CALIFORNIA
}

\author{
D. A. PEPPER ${ }^{1}$
}

\begin{abstract}
Variation in El Niño Circulation Patterns and Winter Storm Impacts in Southern California. El Niño episodes have historically been associated with an increased frequency of extratropical cyclones and cold front passages in Southern California, largely as the result of a southward shift in the Jet Stream. Thus, increases in precipitation, along with hazards, such as flooding and coastal erosion, normally increase during winters when El Niño circulation is strong. However, the strong El Niño episode of 2015-2016 did not confirm this expectation, further contributing to the growing body of evidence that El Niño episodes vary considerably. A common classification system, as outlined by $\mathrm{Yu}$ and Kim (2013), differentiates El Niño circulation modes based on the location of the initial appearance of warm water in the Equatorial Pacific. Quantitative and qualitative analyses are used to assess whether this classification of El Niño episodes is useful in the context of winter storm impacts in California. There is some evidence that Central Pacific (CP) episodes may be associated with higher levels of rainfall than Eastern Pacific (EP) episodes, owing to increased storm duration. Eastern Pacific episodes, most notably in 1982-1983, and 1997-1998, generated energetic waves and caused severe beach erosion, although nearly as much coastal impact was observed during the 2009-2010 CP El Niño episode. Overall the influence of circulation mode appeared to be weak, variation between El Niño years appears to be more strongly determined by the tracks and characteristics of individual winter storms than by overall mode of El Niño circulation. However, since winter storms are the only significant source of precipitation and are the primary cause of episodic coastal erosion in Southern California, further study of the differing effects of EP and CP El Niño episodes is crucial for planning for the future in the region.
\end{abstract}

Keywords: El Niño circulation modes, winter storms, coastal erosion, California

\section{INTRODUCTION}

The term El Niño has been used in South America since at least the 1700's to refer to a quasi-periodic warming of the Equatorial Eastern Pacific Ocean that dramatically reduces the productivity of coastal fisheries. During the $20^{\text {th }}$ Century, however, our understanding of El Niño increased dramatically (Glantz, 2000). By the 1970's, scientists had linked El Niño to shifts in pressure and wind in the Equatorial Pacific, and the collective phenomenon became known as the El Niño-

\footnotetext{
${ }^{1}$ Department of Geography, California State University Long Beach, Long Beach, California, USA, 90840. Email: David.Pepper@csulb.edu.
} 
Southern Oscillation (ENSO). By the mid-1980's, researchers had coined the term "La Niña" to describe El Niño's counterpart, and it became widely recognized that El Niño and La Niña are not deviations from a normal "background" state, but the two ends or phases of the same oscillation (Philander, 1985).

Despite widespread recognition that ENSO is an oscillation, researchers tend to focus on the "warm episodes" known as El Niño. Geographical differences in the impacts of El Niño compared to La Niña may partially account for this, but an even more compelling explanation is the dominance of El Niño phases in both frequency and magnitude during the past 40 years (Fig. 1). In fact, El Niño first received truly global attention in 1982-1983, when the strongest measured phase of El Niño up to that time was linked with drought in Australia and Southeast Asia, flooding in South America, unusual storminess in the Western United States, and a doubling of tropical cyclone activity in the South Pacific (Glantz, 2000).

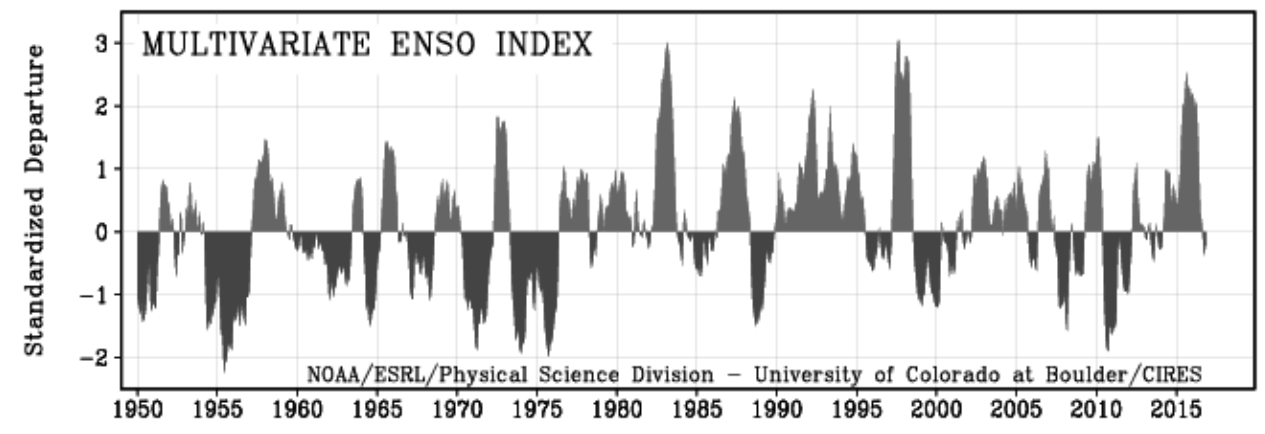

Fig. 1. Multivariate ENSO Index, 1950-2016. Positive values indicate EI Niño circulation. (Data/image and explanation of MEI provided by the NOAA/OAR/ESRL PSD, Boulder, Colorado, USA, at https://www.esrl.noaa.gov/psd/enso/mei/)

During the past decade, researchers have suggested that different types" of El Niño can occur. The "canonical" version involves an increase in sea surface temperature originating in the Eastern Pacific, but in some cases, warming seems to originate in the Central Pacific. This circulation pattern has been called Warm Pool El Niño (Kug et al, 2009), El Niño Modoki (Ashok et al, 2007), or the Central Pacific (CP) El Niño (Yu and Kim, 2013). There appears to be little consensus on how different modes of El Niño may affect regional atmospheric circulation. According to Weng et al. (2007) CP El Niño may have the opposite impact of Eastern Pacific (EP) El Niño, whereas others have argued that impacts in North America during CP El Niño may be comparable to EP El Niño (Barnard et al., 2011).

Yu and Kim (2013) used a pattern correlation method to classify all El Niño episodes between 1870 and 2010 as EP, CP, or mixed circulation types. Interestingly, they noted that there has been a shift from a preponderance of EP El Niño episodes during the $19^{\text {th }}$ Century toward the dominance of CP circulation during the $21^{\text {st }}$ Century. Although it is premature to conclude that this represents a 
long-term shift toward a CP mode of circulation, this trend may be an important factor in how we evaluate the geographical impacts of El Niño. The following paper will attempt to identify whether EP, CP, and mixed El Niño episodes have had significantly different impacts on rainfall, storm occurrence, and coastal erosion in Southern California.

\section{IMPACTS ON SOUTHERN CALIFORNIA}

Coastal Southern California has a Mediterranean climate, with hot and dry summers. Nearly all annual precipitation occurs as a result of winter storms, including mid-latitude cyclones and cold front passages, which migrate onshore from the Pacific between October and April. Owing to the wintertime concentration of precipitation the "water year" is defined as July 1-June 30. On average, Los Angeles receives $375 \mathrm{~mm}$ of rainfall per "water year", but this varies considerably based on winter storm frequency. The trajectory of winter storms is determined largely by strength and position of quasi-stationary high and low pressure systems over the North Pacific and Western North America, which in turn are strongly linked to the phase of ENSO (Storlazzi and Griggs, 1998). The conventional wisdom is that storms are more frequent in the Pacific Northwest (Washington and British Columbia) during neutral or La Niña years, while during El Niño conditions, storms are steered further south, striking the coasts of California and northern Mexico. El Niño is considered a mixed blessing in Southern California, potentially providing much needed moisture to a perpetually water-starved region, but also causing slope failures, coastal erosion, and flooding.

Storlazzi and Griggs (1998), for example showed that $75 \%$ of the damaging storms along the Central California Coast occurred during El Niño episodes, with an average of 1.2 events/year compared to only 0.3 event/year during the other years. They found that there was a nonlinear correlation between ENSO intensity and wave height, sea level, and precipitation and argued that ENSO is one of the primary factors causing coastal change in the region.

\section{DATA AND METHODS}

Classification of El Niño circulation modes into Eastern Pacific (EP), Central Pacific (CP), or Mixed (M), follows that of Yu and Kim (2013), who identified seven EP, sixteen CP, and fifteen mixed episodes between 1870 and 2010. The El Niño episode of 2015-2016 initially showed CP circulation but evolved into a typical EP episode, and is characterized as mixed for the purposes of this discussion.

Precipitation records for Los Angeles Airport (LAX) between 1877 and 2015 were retrieved from the National Centers for Environmental Data. Differences in precipitation between EP, CP, and mixed circulation years were assessed using a one-way analysis of variance (ANOVA) test. 
Long-term coastal erosion data with sufficient temporal resolution were not available to allow a quantitative comparison of coastal impacts during different modes of El Niño circulation. Nonetheless, it is widely recognized that the EP El Niño episodes of 1982-1983 and 1997-1998 were two of the most severe intervals of coastal erosion in Southern California's recorded history (Storlazzi et al., 2000). However, the CP episode of 2009-2010 was also characterized by marked erosion of shorelines in the region, and may even have been nearly as significant as during the earlier EP episodes (Barnard et al., 2011).

Four specific episodes: 1997-1998 (EP), 2004-2005 (CP), 2009-2010 (CP), and 2015-2016 (M), were considered in greater detail based on precipitation and coastal erosion data. Winter storms striking the California coast during these years were identified and classified based on daily synoptic weather maps issued by the National Weather Service. For the purposes of this study, storms were classified in a mutually exclusive manner, either as mid-latitude cyclones (MC) or cold fronts (CF), according to the type of system seen crossing the California coastline on the daily weather map. In cases of wave cyclones, where both a cyclone and front were present, the storm was always recorded as a mid-latitude cyclone. Wind and wave data from the National Data Buoy Center (NDBC) for Station \#46025 in the Santa Monica Basin were also examined in conjunction with these storm occurrences, however, these measurements were not used to classify MC or CF events.

\section{RESULTS}

Rainfall was highest, with an average of $519.5 \mathrm{~mm}$, during years when CP circulation occurred, followed by EP episodes (422.2 mm), mixed episodes, (364.7 $\mathrm{mm}$ ) and non-El Niño years (351.2 mm). However, the difference between CP, EP, and mixed circulation modes was not statistically significant at the $95 \%$ confidence level $(p=0.14)$. This appears to be attributable to high inter-annual variability. For example, annual rainfall during CP episodes ranged from 196.6 to $964.2 \mathrm{~mm}$.

Table 1 shows the strength, peak timing and duration of the four El Niño episodes under consideration, based on the Multivariate ENSO Index (MEI).

Table 1. Multivariate ENSO Index (MEI) for four EI Niño episodes. Values greater than 1.0 indicate EI Niño, and values greater than 2.0 indicate strong EI Niño circulation

\begin{tabular}{|c|c|l|l|}
\hline Year & Maximum MEI & Peak Timing & Duration (MEI > 1.0) \\
\hline 1997-1998 (EP) & 3.044 & Aug/Sept 1997 & May 1997 - June 1998 \\
\hline 2004-2005 (CP) & 1.055 & Feb/Mar 2005 & Feb - Mar 2005 \\
\hline 2009-2010 (CP) & 1.521 & Jan/Feb 2010 & Oct 2009 - Mar 2010 \\
\hline 2015-2016 (M) & 2.530 & Aug/Sept 2015 & April 2015 - June 2016 \\
\hline
\end{tabular}

The 1997-1998 and 2015-2016 episodes were both considered strong events that lasted just over one year, with maximum MEI values occurring in 
August/September. However, their evolution appears to have been somewhat different, with the 2015-2016 episode beginning as a weak CP event before shifting toward an EP circulation mode. The 2004-2005 and 2009-2010 CP El Niño episodes were both weaker in magnitude and shorter in duration, with peaks occurring during the winter.

Table 2 indicates that the four years under study differed considerably in total rainfall, days of rainfall, and maximum daily rainfall. The EP episode and the 2004-2005 CP episode had rainfall totals that were two to three times higher than the annual average, while the mixed episode generated about $50 \%$ less rainfall than average. Despite $176 \mathrm{~mm}$ of additional precipitation, the 2004-2005 CP episode experienced ten fewer rainy days than the EP episode, indicating greater overall rainfall intensity. The highest single-day rainfall total measured during any of the four study periods occurred on December 29, 2004, which actually preceded the official onset of El Niño conditions by more than one month.

Table 2. Rainfall totals, days of rainfall, and maximum daily rainfall event

\begin{tabular}{|c|c|c|c|c|}
\hline Year & Rainfall Total (mm) & Days of Rainfall & Max. Daily Rainfall (mm) & Date \\
\hline $\mathbf{1 9 9 7 - 1 9 9 8}(\mathbf{E P})$ & 788 & 68 & 79 & 4-Feb \\
\hline $\mathbf{2 0 0 4 - 2 0 0 5}(\mathbf{C P})$ & 964 & 58 & 105 & 29-Dec \\
\hline $\mathbf{2 0 0 9 - 2 0 1 0}(\mathbf{C P})$ & 416 & 39 & 47 & 5-Feb \\
\hline $\mathbf{2 0 1 5 - 2 0 1 6}(\mathbf{M})$ & 245 & 36 & 36 & 5-Jan \\
\hline
\end{tabular}

Table 3 summarizes wind and wave conditions recorded during the study intervals by the National Data Buoy Center (NDBC) at Station \#46025 in the Santa Monica Basin.

Table 3. Wind speed and wave height during the four episodes. Note that the values are given for the 12-month "water years" associated with each episode

\begin{tabular}{|l|c|c|c|c|c|}
\hline & \multicolumn{2}{|c|}{ Wind Speed (ms $\left.\mathbf{- 1}^{\mathbf{1}}\right)$} & \multicolumn{2}{c|}{ Wave Height (m) } & Erosion \\
\hline Year & Mean & Maximum & Mean & Maximum & Qualitative Assessment \\
\hline $\mathbf{1 9 9 7 - 1 9 9 8 ~ ( E P ) ~}$ & 4.83 & 18.5 & 1.58 & $5.34(3-\mathrm{Feb})$ & High \\
\hline $\mathbf{2 0 0 4 - 2 0 0 5}(\mathbf{C P})$ & 3.73 & 14.7 & 1.14 & $3.90(28-\mathrm{Dec})$ & Low \\
\hline $\mathbf{2 0 0 9 - 2 0 1 0}(\mathbf{C P})$ & 3.76 & 18.4 & 1.24 & $4.53(28-\mathrm{Feb})$ & High \\
\hline $\mathbf{2 0 1 5 - 2 0 1 6}(\mathbf{M})$ & 3.91 & 19.9 & 1.19 & $4.45(1-\mathrm{Feb})$ & Low \\
\hline
\end{tabular}

The EP episode of 1997-1998 was unusually energetic, with a notably higher average wind speed and particularly, significant wave height, than the other intervals. Significant wave height on February 3, 1998 reached $5.34 \mathrm{~m}$, considerably in excess of all other intervals. The CP episode of 2004-2005 was the least energetic in all categories. Qualitative assessments of coastal erosion are consistent with these measurements. The El Niño episodes of 1997-1998 and 
2009-2010 are widely considered to have been characterized by the most severe coastal erosion of at least the past 25 years. On the other hand, there is little evidence of enhanced erosion in 2004-2005 or 2015-2016.

Table 4 represents a qualitative assessment of winter storms striking the California coast during the study intervals, based on daily synoptic weather maps issued by the National Weather Service. For the purposes of this study, storms are classified in a mutually exclusive manner, either as mid-latitude cyclones (MC) or cold fronts (CF), based on the type of system seen crossing the California coastline on the daily weather map. In cases of wave cyclones, where both a cyclone and front are present, the storm is always recorded as a mid-latitude cyclone. Although these storm occurrences were typically also observable in meteorological and wave data recorded digitally, these measurements were not used specifically as criteria to identify MC or CF occurrences.

Table 4. Mid-Latitude Cyclone (MC), Cold Front (CF), and Overall Storm Occurrences on Coastal California, Based on Daily Synoptic Weather Maps

\begin{tabular}{|c|c|c|c|}
\hline Year & MC & CF & Total Storms \\
\hline $\mathbf{1 9 9 7 - 1 9 9 8}(\mathbf{E P})$ & 9 & 19 & 28 \\
\hline $\mathbf{2 0 0 4 - 2 0 0 5}(\mathbf{C P})$ & 7 & 14 & 21 \\
\hline $\mathbf{2 0 0 9 - 2 0 1 0}(\mathbf{C P})$ & 14 & 20 & 34 \\
\hline $\mathbf{2 0 1 5}-2016(\mathbf{M})$ & 7 & 21 & 28 \\
\hline
\end{tabular}

Migrating cyclone were most frequent during the CP episode of 2009-2010, followed by the EP episode of 1997-1998. The greatest number of storms overall also occurred in 2009-2010, while the fewest storms of each kind occurred during the CP episode of 2004-2005. The mixed episode of 2015-2016 generated the most frequent cold front passages, and an equal number of storms overall as 1997-1998.

\section{DISCUSSION}

Numerous quantitative and qualitative factors have been considered in this analysis, but it has become clear that these cannot adequately explain the relevant processes affecting rainfall and coastal erosion in Southern California. For example, the El Niño episodes of 1997-1998 and 2015-2016 were similar in strength, duration, and to some degree, circulation pattern. The same number of storm impacts occurred in Southern California during these years, and yet 19971998 was associated with heavy precipitation and historic levels of coastal erosion, while 2015-2016 was drier than average, and coastal impacts appear to have been quite mild. The best analogue for 1997-1998 may be the relatively weak, yet stormy, CP episode of 2009-2010.

The notion that CP episodes are especially wet is not particularly convincing. Although the CP episode that occurred during 2004-2005 produced the 
wettest year since 1883-1884, it was a weak and short-lived, and the heaviest rainfall occurred prior to the onset of true El Niño circulation.

It is possible in some cases to find specific explanations that can partially account for some of this variability. Despite the occurrence of an unremarkable number of storms in 1997-1998, several were particularly powerful. The midlatitude cyclone that struck Los Angeles on February 2-3, 1998, generated swirling, gusty winds and a complex wave field with a significant wave height of over five meters, resulting in extensive coastal flooding and sediment loss. The near-record level of rainfall that occurred in 2004-2005 is attributable to a series of storm systems in late December and early January that stalled over Southern California, most notably, a stationary front that caused rainfall for five straight days - an unusual occurrence in Southern California under any circumstances. The El Niño episode that occurred in 2015-2016 was perhaps a different type of circulation pattern altogether. Most notably, researchers identified an unusual accumulation of warm water off the California coast known as "the blob", which may have had a stronger impact than El Niño itself (Jacox et al., 2016).

More broadly, there are difficulties in trying to explain localized occurrences entirely on the basis of patterns of global circulation. Rainfall and coastal processes in Southern California during any particular year are heavily influenced by a few high-intensity, but low frequency, events. While shifts in storm tracks associated with El Niño circulation certainly influence the likelihood of rainfall and/or coastal erosion in Southern California, there are countless other factors involved, so it is at best considered a probabilistic, rather than a deterministic system. Coastal erosion, in particular, is hard to evaluate since sediment transport is not linearly correlated with meteorological or hydrodynamic factors such as wind velocity or wave height. Increased hydrodynamic energy can produce erosion as well as aggradation, and beaches themselves seek equilibrium with prevailing wave conditions. Moreover, human activity is a key variable in all coastal systems.

\section{CONCLUSION}

The purpose of this paper has been to further explore the relationship between different El Niño circulation modes and potential impacts on Southern California. This research is somewhat preliminary, but it highlights both the potential and the limitations of using different types of El Niño (Eastern Pacific, Central Pacific, Mixed), in a local or regional context. It is clear that El Niño itself has an important influence on storminess, precipitation, and coastal erosion in Southern California, although this effect is highly variable and may depend on the occurrence of a small number of intense storms. It is possible that different modes of El Niño will ultimately be shown to have differing influences, but further research on the specifics of this relationship and consideration of additional factors is necessary. 


\section{REFERENCES}

1. Ashok, K., Behera, S.K., Rao, S.A., Weng, H., \& Yamagata, T. (2007). El Niño Modoki and its possible teleconnections. J. Geophysical Res. 112, C11007

2. Barnard, P. L., J. Allan, J. E. Hansen, G. M., Kaminsky, P. Ruggiero, \& A. Doria (2011) The impact of the 2009-10 El Niño Modoki on U.S. West Coast beaches. Geophysical Research Letters 38, L13604.

3. Glantz, M.H. (2000). Currents of Change: Impacts of El Niño and La Niña on Climate and Society (2e.). Cambridge, U.K.: Cambridge University Press.

4. Jacox, M.G., Hazen, E.L., Zaba, K.D., Rudnik, D.L., Edwards, C.A., Moore, A.M., \& Bograd, S.J. (2016) Impacts of the 2015-2016 El Niño on the California Current System: Early assessment and comparison to past events. Geophysical Research Letters 43, 13, 7072-7080.

5. Kug, J.-S., Jin, F.-F., \& An, S.-I. (2009) Two types of El Niño Events: Warm Pool El Niño and Cold Tongue El Niño. J. Climate 22, 1499-1514.

6. National Centers for Environmental Information: https://www.ncdc.noaa.gov/ (01/12/2017)

7. National Data Buoy Center: http://www.ndbc.noaa.gov/ (01/02/2017)

8. National Weather Service: http://www.weather.gov/ (01/10/2017)

9. Philander, S. G. H. (1985) El Niño and La Niña. Journal of Atmospheric Science, 42, 2652-2662.

10. Storlazzi, C.D. \& Griggs, G.B. (1998). Influence of El Niño-Southern Oscillation (ENSO) Events on the Coastline of Central California. Journal of Coastal Research, 26, 146-153

11. Storlazzi, C.D., Willis, C.M. \& Griggs, G.B. (2000). Comparative impacts of the 1982-83 and 1997-98 El Niño winters on the central California coast. Journal of Coastal Research 16, 4, 1022-1036

12. Weng, H., Ashok, K., Behera, S.K., Rao, S.A., \& Yamagata, T. (2007). Impacts of recent El Niño Modoki on dry/wet conditions in the Pacific rim during boreal summer. Climate Dynamics 29, 113-129.

13. Yu, J.-Y. \& Kim, S.T. (2013) Identifying the types of major El Niño events since 1870. International Journal of Climatology 33, 2105-2112 